\title{
SEXUAL RISK BEHAVIOURS AND STI RISK PERCEPTION AMONG SENIOR HIGH SCHOOL STUDENTS IN THE SUNYANI MUNICIPALITY OF GHANA
}

\author{
Antwi Joseph Barimah1, Mohammed Mohammed Ibrahim², Yaw Boakye Nketiah', \\ Bernard Opoku Amoah', Larry Agyemang5, James Dumba', and Helina Gyamea ${ }^{7}$
}

College Of Health Yamfo-Ghana

\begin{abstract}
Quabenabarimah89@yahoo.com¹, Mimkp2004@yahoo.com², Boakyenana14@gmail.com³, bopokuamoah@gmailcom ${ }^{4}$, Laray0111@gmail.com ${ }^{5}$, dumjames28@gmail.com ${ }^{6}$, and gymeaah@yahoo.com ${ }^{7}$
\end{abstract}

\section{Copyrights}

Copyright for this article is retained by the author, with first publication rights granted to the journal. This is an open-access article distributed under the terms and conditions of the Creative Commons Attribution license

(http://creativecommons.org/licenses/by/4.0/)

\begin{abstract}
In the ideal world scenario risky sexual behaviours are rampant. The most worrying part is the fact that teenagers and the youth are the ones with a high predisposition to indulge in risky sexual behaviours. This study assessed the risky sexual behaviour and the STI Risk Perception among senior high school students within the Sunyani municipality. Descriptive cross-sectional study design was deployed in order to get a clear picture of the relationship between risky sexual behaviour and the attendant STIs. The targeted population was 250 students of the Twene Amanfo Senior High Technical School (TASTECH) in Sunyani- Ghana. In order to reduce bias, a simple random sampling was used in recruiting the 250 participants. A structured questionnaire was employed in obtaining quantitative data from the students. Statistical Package for the Social Sciences (SPSS version 25) was used to analyze the quantitative data. The results indicated that, 110 students (44\% of respondents) indulged in various forms of sexual risk behaviours. A greater majority of 147 (78.8\%) had low STI risk perception which is very disheartening. Sexual risk behaviours such as early sexual initiation (OR 7.462, CI: 4.143 - 14.096), having multiple sexual partners (OR 43.669, CI: 20.825 - 91.573), non-condom use (OR 6.368, CI: 3.456 - 11.735) and the use of drugs (OR 15.523, CI: 8.226 - 29.292) were strongly associated with the likelihood of contracting sexually transmitted infections. The study therefore recommends that there should be a rigorous mass sensitization campaigns across all Senior High schools in Ghana to create more awareness among young people on the dangers associated with indulging in risky sexual behaviours.
\end{abstract}

Keywords: Risky sexual behaviour, STI Risk Perception, Sexually Transmitted Infections

\subsection{INTRODUCTION}

\subsection{Overview of sexual risk behaviours}

Risky sexual behaviour is defined as the various behaviours that increase the likelihood of an individual's risk of contracting a sexually transmitted infection or unplanned pregnancy (Centre for Disease Control, 2012). Adolescents are often used in such studies since fall within the young age category. It is however worthy of note that adolescents are mostly come mind when the topic of sexual risk behaviour is mentioned and this is due to the high vulnerabilities associated with such age category. Risky sexual behavior is explained as behaviors that have the tendency to predispose an individual into contracting an STI. These behaviors are further elucidated using four key characteristics, which include; having sexual intercourse without using a condom, having sex under the influence of alcohol/drugs, multiple sexual partners and early sexual initiation.

In a study by Kenyon et al (2014), they observed that the incidence and prevalence of STIs is catalyzed by a wider range of factors, which include treatment effectiveness, biological interactions with other STIs, socio-economic and other upstream factors as well as sexual risk behaviors. They further opined those different dynamics of causal factors such as noncondom use, multiple sexual partners, having sex under the influence of alcohol and early sexual initiation, may combine to trigger the increase rate of STI incidence. Hence, rate and extent of the variations 


\section{International Journal of Multidisciplinary Studies and Innovative Research \\ Publisher: Catholic University College of Ghana \\ ISSN: 2737-7172 (0), ISSN: $2737-7180(\mathrm{P})$ \\ DOI: $10.53075 /$ ljmsirq 87965439050 \\ DOI Url: http://doi.org/10.53075//jmsirq87965439050}

in STI incidence are challenges to any effort to classify global populations on the basis of STI prevalence.

Evidence from literature have also shown that multiple sexual partners, non-condom use and drug use have been classified as behavioral factors that are deemed risky for the transmission of STIs worldwide (Brouillette., 2013). Risky behaviours such as excessive alcohol consumption, non-condom use and the multiple number of sexual partners place majority of the youth (adolescent) population at a higher risk of contracting STIs compared to their compatriots who do not indulge in such risky activities (Adefuye et al., 2009).

A study carried out in Indonesia by Rokhmah (2015), among adolescents in the coastal belt found that the risky activities of adolescents and their propensity to transmit HIV and other STIs were made possible from unprotected sexual intercourse with their partners; the proportion of HIV cases mostly occurring among the adolescents accounted for $81.8 \%$. This high percentage buttresses the fact that the youth is a highrisk group and thus must be the targeted group for HIV/AIDS prevention programmes. The study further observed that health-oriented programmes targeting sexual and reproductive health for the youth and other adolescents still remained woefully inadequate (Rokhmah, 2015).

In a meta-analysis study among youthful males in developing countries conducted by Berhan \& Berhan (2015), they observed a significant statistical association of higher-risk sex with male youth younger than 20 years, living in urban centers, well educated, and of a high economic status. The overall proportion of condom use during youths' most recent higher-risk sexual encounter was $40 \%$ and $51 \%$ among 15-19-year-olds and 20-24-year-olds, respectively. These findings further affirm the high spate of risky sexual behaviour among adolescents (Berhan \& Berhan, 2015).

Findings from another important study that was conducted in Ghana on the same subject matter, examined adolescents in urban poor areas in two towns in the Brong Ahafo region and it was found that $29 \%$ of the adolescents sampled indulged in multiple sexual relations. Majority being males (57.6\%) than females (14.9\%) indicated having multiple sexual partners. The study further observed that adolescents in the two communities were indiscriminately engaging in high sexual activities. In spite of this existing menace, condom use among the adolescents was lacking thereby increasing their likelihood of contracting STIs (Darteh \& Nnorom, 2012).

\subsection{STI risk perception}

A report by the Centre for Disease Control (CDC) in 2012 revealed that there are three practices that enhance and trigger most cases of death and sickness among the youth, these include; violence and injuries, alcohol and drug use and risky sexual behaviours. Indulging in risky sexual behaviour means that young people do not consider the negative health consequences associated with it but rather look out for the related quick pleasure that accompanies risky sexual behaviours.

In a study by Kugbey at el (2018) they explored the causes related to the risk perception of getting STIs and took into account high level of knowledge about STIs, being male and having had signs of STIs in last 6 months. The researchers after controlling for confounders, in a multivariate logistic regression analysis found that the supposed risk of getting an HIV alone was significantly associated with gender (being male), having in-depth knowledge about STIs, and knowledge about HIV. The findings supported the need to target the youth for STIs/HIV prevention programs by dealing with the wrong perception of risk and increasing awareness on STIs/HIV since socio-demographic characteristics such as gender, knowledge of STIs/HIV and the level of disclosure of STIs signs were the main determining factors of risk perceptions of STIs.

A study conducted in the Rwandan province of Gikongoro revealed that a greater majority comprising $85 \%$ of the study participants knew somebody who had died of AIDS, yet, about $68.9 \%$ indicated that they were at no risk of contracting an HIV infection and a meager $3.2 \%$ indicated that they were at a high risk of contracting an HIV infection. This is very alarming considering its negative repercussions (Ntaganira et al., 2012). The notion of sex and the inclination that the youth see themselves as not at danger of getting STIs including HIV raises a major issue that needs to be addressed urgently and swiftly.

In Ghana, it has been reported in literature that the most frequent sexually transmitted infections have the tendency to be higher among young women than among men. Considering the impact of sexually transmitted infections on HIV infections, the youth, 


\section{International Journal of Multidisciplinary Studies and Innovative Research \\ Publisher: Catholic University College of Ghana \\ ISSN: 2737-7172 (O), ISSN: 2737-7180 (P) \\ DOI: $10.53075 /$ ljmsirq 87965439050 \\ DOI Url: http://doi.org/10.53075/ljmsirq87965439050}

especially young women are at increasing risk of contracting an STI including HIV (Okonta et al., 2013).

This study therefore aimed at investigating risky sexual behaviour and its associated sexually transmitted infections. Risky sexual behaviour and the attendant sexually transmitted infections especially HIV remains one of the leading causes of death globally, yet not much research work has been done concerning it in the Sunyani Municipality. This study sought to give an idea of what risky sexual behaviour is and its negative associated repercussions (STIs) in the Sunyani municipality using Twene Amanfo Senior High Technical School as the case study since it is not known by any study.

\subsection{MATERIALS AND METHODS}

\subsection{Research design}

Descriptive cross-sectional study design was deployed for this study. The study utilized the descriptive study design with the view of getting the clear picture of the relationship between risky sexual behaviour and attendant STIs. A cross-sectional study is an observational and a non-interventional study which involves gathering data from a cross-section of a population over a short period of time or in a single point in time.

\subsection{Sampling technique and sample size}

It is difficult to use an entire population for a study and this requires the use of a sample of a population. Sampling involves the selection of a number of observations from the target population. In order to reduce bias, a simple random sampling technique which is a probability-based sampling technique was used in selecting 250 students from the Twene Amanfo Senior High Technical School.

The sample size was determined using the Cochran formula at $95 \%$ confidence level and estimated prevalence (p) at $20 \%(0.2)$.

$$
\begin{aligned}
& \mathrm{N}=\mathrm{Z}^{2} p \mathrm{q} / \mathrm{e}^{2} \\
& \mathrm{~N}=1.96^{2} * 0.2(1-0.2) /(0.05)^{2} \\
& \mathrm{~N}=0.615 / 0.0025 \\
& \mathrm{~N}=245.86, \text { approximately } \mathbf{2 5 0}
\end{aligned}
$$

\subsection{Data collection procedure}

The data collection was done in English, Twi and the local Bono language where necessary to enhance thorough understanding of the questions. The data collection was done by the researcher and two (2) research assistants who were adequately trained regarding the overall research in order to have indepth knowledge about the study.

In order to ensure data validity and reliability, two (2) research assistants were adequately trained three (3) days prior to pre-testing and the final data collection regarding the overall research in order to have indepth knowledge about the study. The training was thus to ensure their thorough understanding of the research topic, objectives and the sensitivity of the topic and need for confidentiality of information provided by respondents. The training was also to ensure they diligently and effectively administer the questionnaires. Prior to data collection, the overall goal of the study was thoroughly explained to the students in order to gain their informed consent. Students who were willing to participate in the study were given questionnaires to answer with consistent assistance from the researchers and the research assistants.

\subsection{Data analysis}

Statistical Package for the Social Sciences (SPSS version 25) is the data analysis tool that was used to analyze quantitative data of this study. Questionnaires after being collected was thoroughly checked through to ensure all questions were accurately answered and errors were corrected to ensure completion before entering it into the SPSS for rigorous data analysis. Descriptive analysis was done at the univariate and multivariate levels and data was presented in frequencies using tables and figures. 
International Journal of Multidisciplinary Studies and Innovative Research

Publisher: Catholic University College of Ghana

ISSN: 2737-7172(0), ISSN: 2737-7180(P)

DOI: $10.53075 /$ ljmsirq 87965439050

DOI Url: http://doi.org/10.53075/ljmsirq87965439050

\subsection{RESULTS}

\subsection{Demographic characteristics of respondents}

Table 1; Socio-demographic characteristics of respondents

\begin{tabular}{llcc}
\hline Variable (s) & Category & Frequency (N=250) & Percent (\%) \\
\hline Age Group & $12-15$ years & 49 & 19.6 \\
& $16-19$ years & 136 & 54.4 \\
& Above 19 years & 65 & 26.0 \\
Sex & Male & & 58.0 \\
& Female & 145 & 42.0 \\
Religion & & 105 & 80 \\
& Christianity & 200 & 18.4 \\
& Islam & 46 & 1.6 \\
Relationship status & Judaism & 4 & 48.4 \\
& Single & 121 & 51.6 \\
\hline
\end{tabular}

A total of 250 respondents participated in this study. From table 1 above, the findings indicate that, most $136(54.4 \%)$ of the respondents fall within the age category $16-19$ years but the least $49(19.6 \%)$ were within 12 - 15 years. Majority, 129(51.6\%) of the respondents were found be in sexual relationship and the rest $121(48.4 \%)$ were not. A good majority of the respondents $200(80.0 \%)$ were Christians, 46 (18.4\%) were Muslims while only $4(1.6 \%)$ were practicing Judaism religion. Males constituted the dominant group with $145(58.0 \%)$ and the females were 105(42.0\%).

\subsection{Sexual risk behaviours}

\subsubsection{Proportion of students who indulge in risky sexual behaviors}

The proportion of students who indulge in risky sexual behavior was determined under seven questions.

Table 2; Indulging in risky sexual behavior

\begin{tabular}{llcc}
\hline Variable (s) & Category & Frequency & Percent (\%) \\
\hline Have many sexual partners & one & 86 & 34.4 \\
& two & 36 & 14.4 \\
& $2+$ & 7 & 2.8 \\
Had unprotected sex & Yes & 90 & 36.0 \\
Age of First Intercourse & No & 20 & 8.0 \\
& $14-15$ years & 21 & 8.4 \\
Had sex in last 12 months & $16-19$ years & 89 & 35.6 \\
& Yes & 68 & 27.2 \\
$\begin{array}{l}\text { Last 12 months had sex while } \\
\text { drunk }\end{array}$ & No & 42 & 16.8 \\
& Yes & 20 & 8.0
\end{tabular}


International Journal of Multidisciplinary Studies and Innovative Research

Publisher: Catholic University College of Ghana

ISSN: 2737-7172 (O), ISSN: 2737-7180 (P)

DOI: $10.53075 /$ ljmsirq 87965439050

DOI Url: http://doi.org/10.53075/ljmsirq87965439050

\begin{tabular}{llcc} 
& No & 90 & 36.0 \\
$\begin{array}{llc}\text { Used drugs, smoke, alcoholic } \\
\text { in last 12 months }\end{array}$ & Yes & 12 & 4.8 \\
& No & 98 & 39.2 \\
Had Sex for Cash & Yes & 40 & 16.0 \\
& No & 70 & 28.0 \\
Total & & $\mathbf{2 5 0}$ & $\mathbf{1 0 0 . 0}$ \\
\hline
\end{tabular}

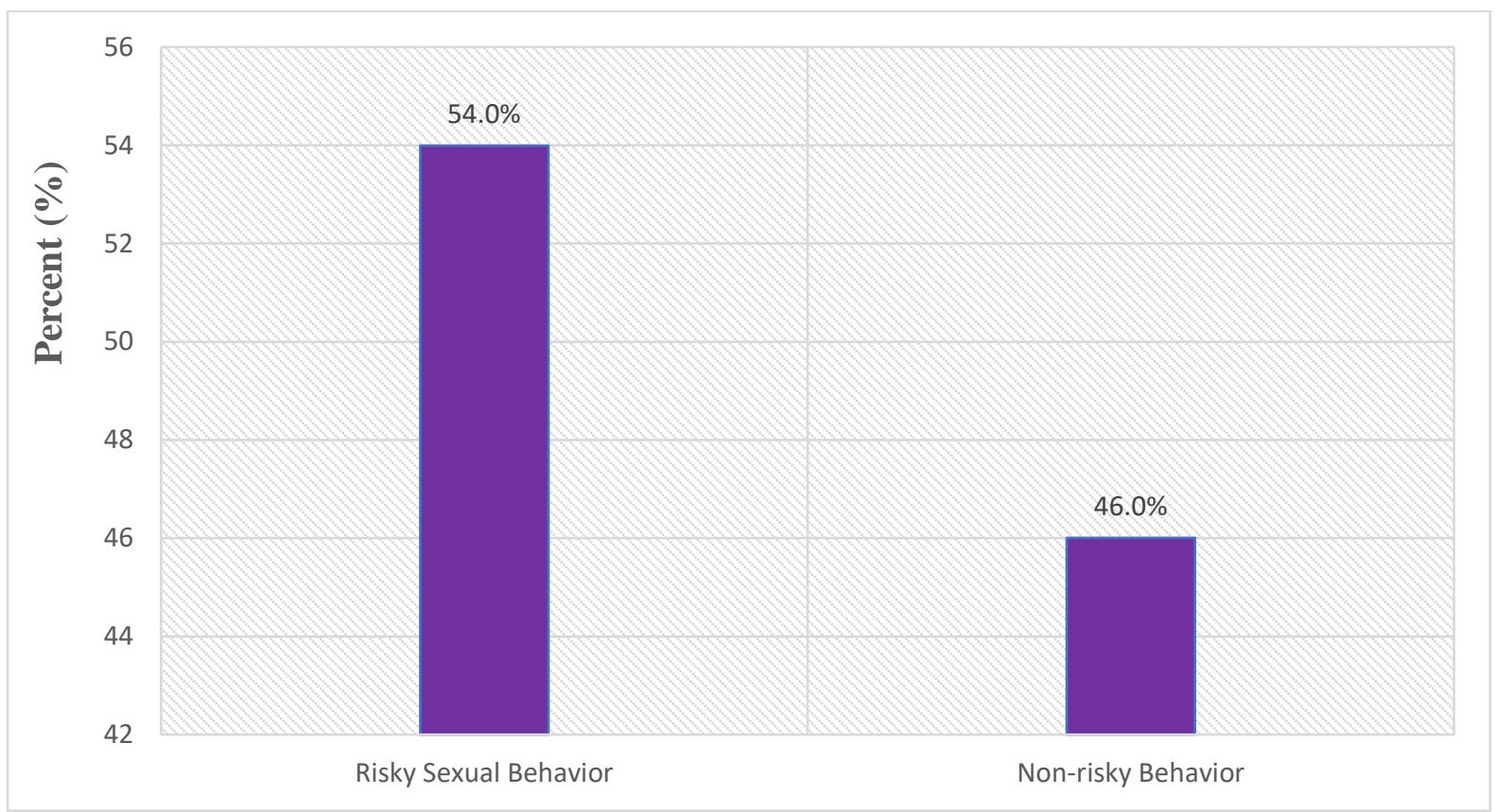

Figure 1; Proportion of students who indulge in risky sexual behavior

The findings in table 2 and figure 1 above indicate that, out of the 110 students who ever had sexual intercourse, $56 \%$ indulged in risky sexual behavior such as having more than one sexual partner, having unprotected intercourse, having sex while drunk, taking drugs, alcohol and others and involving in sex for cash whilst $46 \%$ never involved in risky behavior.

\subsubsection{Types of sexual risk behaviours practiced by students}

The various risky sexual behaviors of students were assessed and the outcomes are presented in the graphs below. 


\section{International Journal of Multidisciplinary Studies and Innovative Research}

Publisher: Catholic University College of Ghana

ISSN: 2737-7172(0), ISSN: 2737-7180(P)

DOI: $10.53075 /$ ljmsirq 87965439050

DOI Url: http://doi.org/10.53075/ljmsirq87965439050

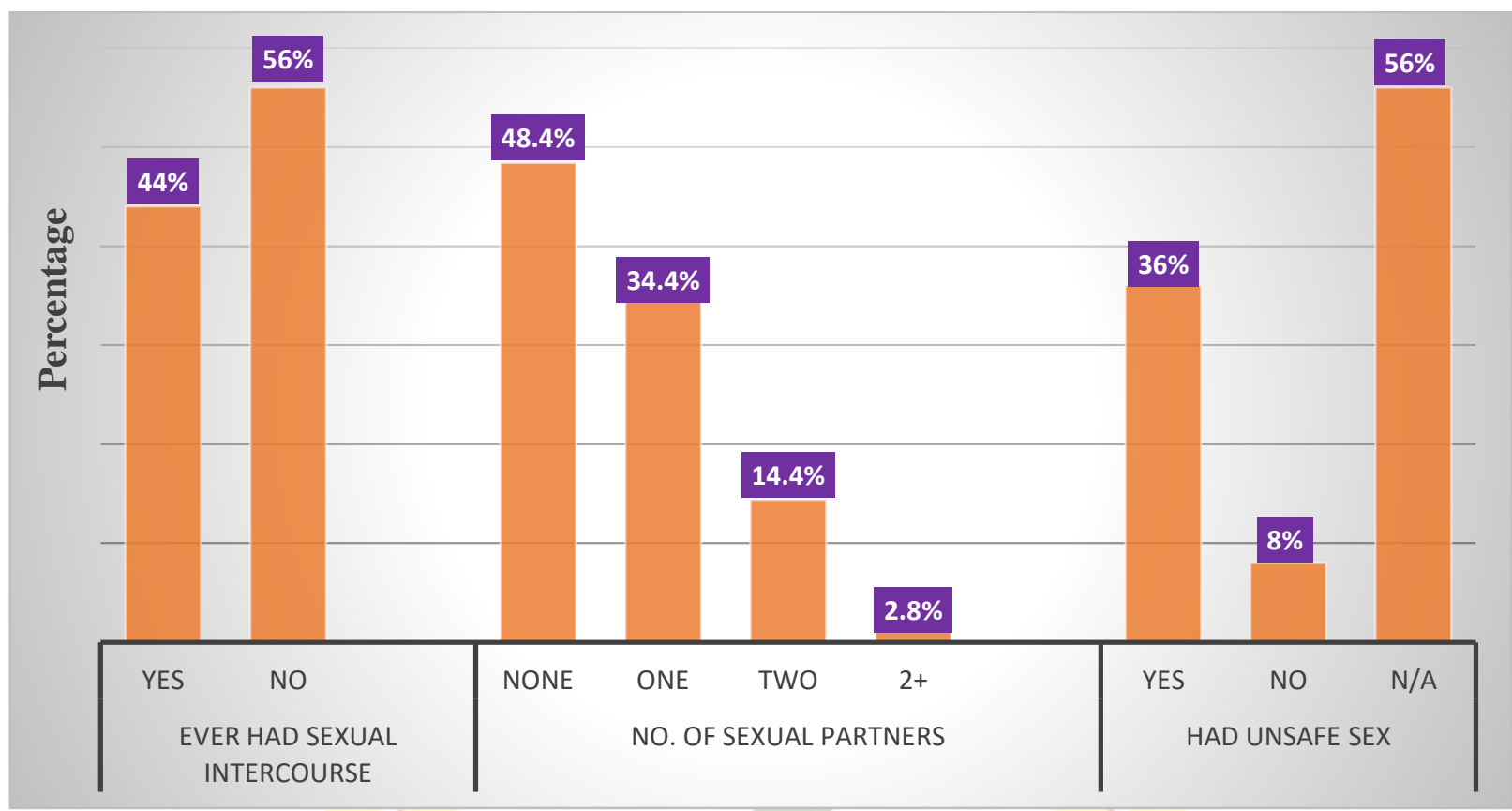

Figure 2; Sexual intercourse among study participants

The results indicate, $56 \%$ of the students never had sexual intercourse and $44 \%$ had intercourse. Out the $44 \%$ of the students who ever had sexual intercourse, $34.4 \%$ had only one partner, $14.4 \%$ had two sexual partners and only $2.8 \%$ had more than two sexual partners. Also, out of the $44 \%$ who ever had sexual intercourse, almost all of them (36\%) had unprotected sex and only $8 \%$ practiced safe sex by using condoms (see figure 2 ).

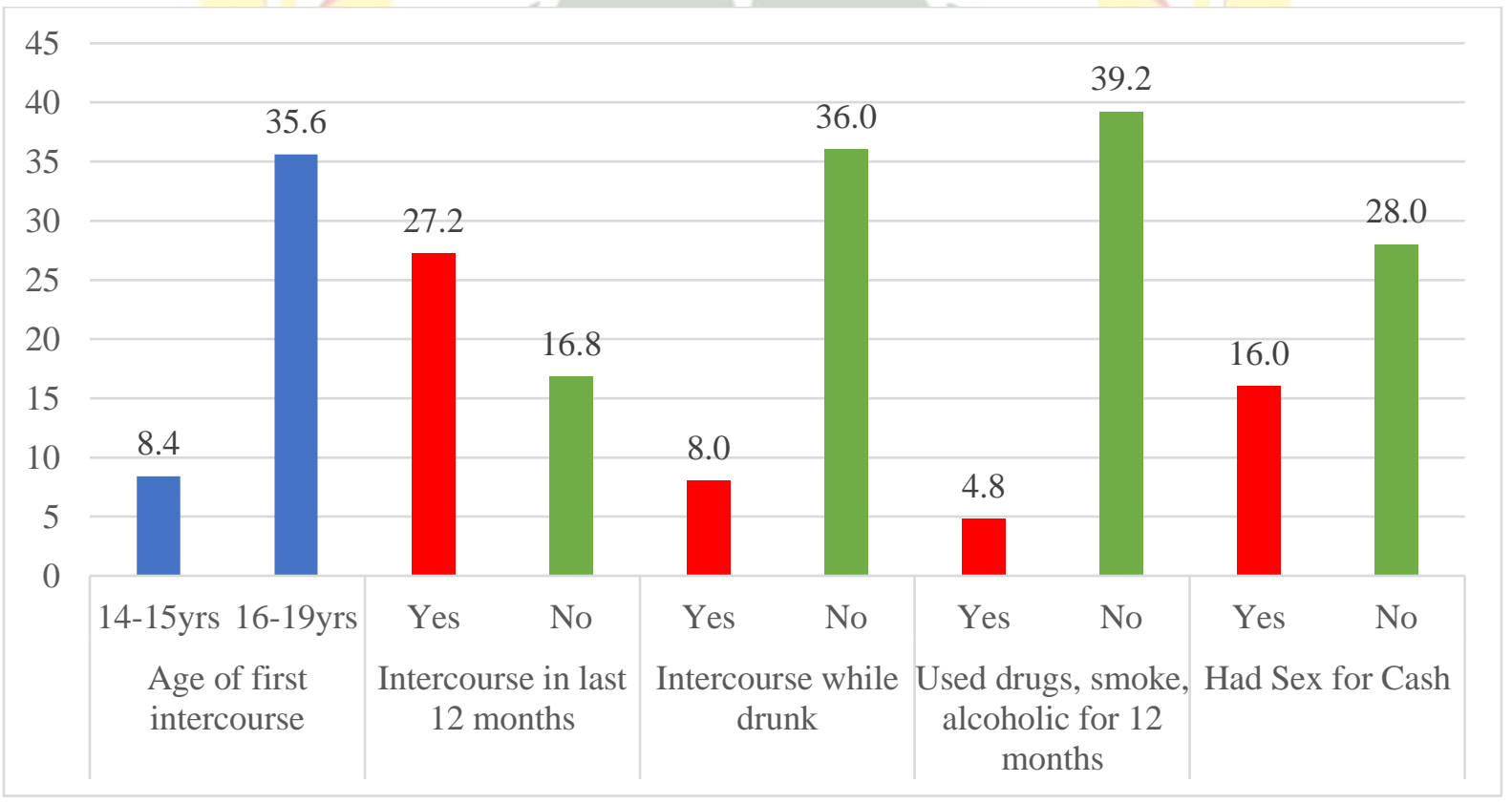

\section{Figure 3: Risky sexual behaviours}

The results in figure 3 indicate that, 35.6\% of those who ever had sexual intercourse broke their virginity within 16-19 years whereas $8.4 \%$ had their first sexual intercourse at the age of $14-15$ years. However, $27.2 \%$ had sexual intercourse in the last 12 months and 16.8\% haven't had sexual intercourse in the last 12 months. Moreover, majority $36 \%$ were never drunk while having sexual intercourse and only $8 \%$ were in alcoholic state during intercourse. While $4.8 \%$ of the respondents used drugs, alcohol and even smoked within the last 12 months, a 
International Journal of Multidisciplinary Studies and Innovative Research

Publisher: Catholic University College of Ghana

ISSN: 2737-7172 (O), ISSN: 2737-7180 (P)

DOI: $10.53075 /$ ljmsirq 87965439050

DOI Url: http://doi.org/10.53075/ljmsirq87965439050

greater number, $28 \%$ never did that. Furthermore, $16 \%$ of the respondents practiced sex for cash but $28 \%$ did not indulge in sex for money.

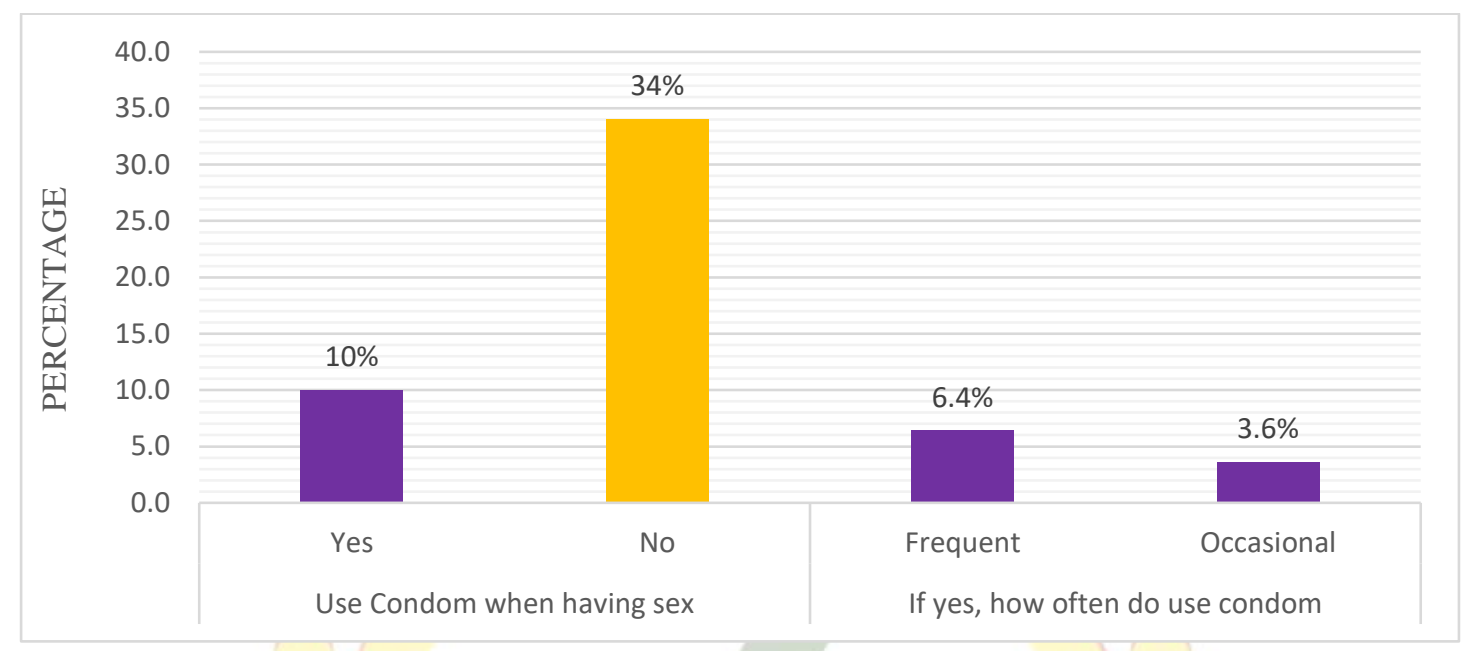

Figure 4; The usage of condom among students

Out of the $44 \%$ of the students who had sexual intercourse, $10 \%$ used condom whilst the remaining (34\%) never used condom during the sexual intercourse. Out of the $10 \%$ who used condom, $6.4 \%$ uses it very frequently whereas 3.6\% only use it occasionally (as shown in Figure 4).

\subsection{STI risk perception among students}

Table 3; STIs risk perception among the students

\begin{tabular}{|c|c|c|c|}
\hline Variable (s) & Category & $\begin{array}{l}\text { Frequency } \\
(n=250)\end{array}$ & Percentage \\
\hline $\begin{array}{l}\text { How do you perceive the prevalence } \\
\text { and incidence of STIS }\end{array}$ & $\begin{array}{l}\text { MS } \\
\text { High } \\
\text { Low } \\
\text { Don't kno }\end{array}$ & 101 & $\begin{array}{l}34.4 \\
29.2 \\
40.4\end{array}$ \\
\hline $\begin{array}{l}\text { Adolescents are more vulnerable to } \\
\text { STIS }\end{array}$ & $\begin{array}{l}\text { Yes } \\
\text { No }\end{array}$ & $\begin{array}{c}182 \\
68\end{array}$ & $\begin{array}{l}72.8 \\
27.2\end{array}$ \\
\hline $\begin{array}{l}\text { I am rationally safe from STIs even } \\
\text { having unprotected sex }\end{array}$ & $\begin{array}{l}\text { Agree } \\
\text { Disagree }\end{array}$ & $\begin{array}{c}82 \\
168\end{array}$ & $\begin{array}{l}32.8 \\
67.2\end{array}$ \\
\hline $\begin{array}{l}\text { I would be worried of getting STIs, if } \\
\text { had unsafe sex }\end{array}$ & $\begin{array}{l}\text { Agree } \\
\text { Disagree }\end{array}$ & $\begin{array}{l}145 \\
105\end{array}$ & $\begin{array}{l}58.0 \\
42.0\end{array}$ \\
\hline $\begin{array}{l}\text { STIs are not dangerous because they } \\
\text { can be cured }\end{array}$ & $\begin{array}{l}\text { Agree } \\
\text { Disagree }\end{array}$ & $\begin{array}{c}79 \\
171 \\
\end{array}$ & $\begin{array}{l}31.6 \\
68.4\end{array}$ \\
\hline
\end{tabular}

The risk perception of students on STIs was determined using 5 statements on STIs risk. From the table 3 above, 76(34.3\%) perceived there was high incidence and prevalence of STIs among the people within the society and a 


\section{International Journal of Multidisciplinary Studies and Innovative Research \\ Publisher: Catholic University College of Ghana \\ ISSN: 2737-7172 (O), ISSN: 2737-7180 (P) \\ DOI: $10.53075 /$ ljmsirq 87965439050 \\ DOI Url: http://doi.org/10.53075/ljmsirq87965439050}

greater percentage 101(40.4\%) had no idea about the STIs incidence and prevalence. Also, $72.8 \%$ perceived adolescents were more vulnerable to STIs whereas $27.2 \%$ disputed that fact. Furthermore, $67.25 \%$ believed they were rationally safe from STIs even after having unprotected sexual intercourse whereas $32.8 \%$ believed they were not safe from STIS. Moreover, 58.0\% of the respondents said they will be worried after having unprotected sex but $42 \%$ will not be worried of getting STIs. More than half (68.4\%) perceived that STIs are dangerous and cannot be cured whilst $31.6 \%$ perceived STIs are not dangerous.

Table 4; Rating the students STI risk perception among the students

\begin{tabular}{lcc}
\hline Sexual Behavior & Frequency & Percentage (\%) \\
\hline High STIs Risk Perception & 53 & 21.2 \\
Low STIs Risk Perception & 197 & 78.8 \\
Total & 250 & 100 \\
\hline
\end{tabular}

In assessing the overall risk perception of the respondents towards STIS, five (5) statements were rated. Out of the 5 statements, a score of (3-5) indicated high risk perception while a score of (0-2) indicated low risk perception. The scores were then converted into percentages. (See table 4)

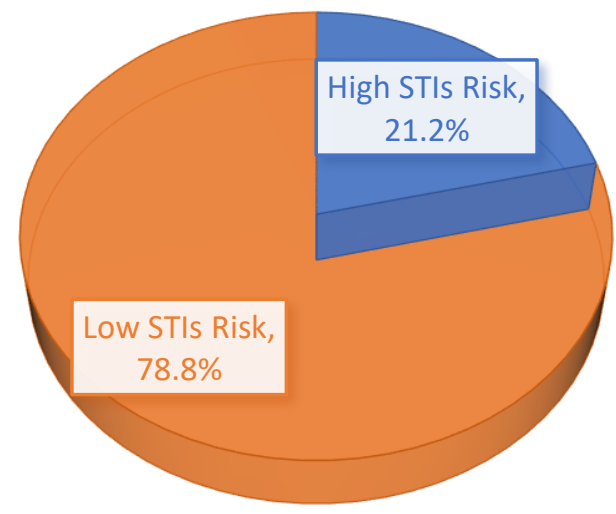

High STIs Risk $\quad$ Low STIs Risk

Figure 5; Respondents Overall STI Risk Perception

The results for the overall STIS risk perception of respondents are presented in the figure above. The results indicate that, only, $21.2 \%$ were found to have high STIS risk perception whereas a greater majority of $78.8 \%$ had low STIs risk perception (see figure 5).

3.4 Association between sexual risk behaviours and the development of STIs

Table 5; Relationship between sexual risk behaviours and STIS

\begin{tabular}{lccc}
\hline & \multicolumn{3}{c}{ Development of STIs } \\
\hline Sexual risk behaviours & Yes & No & P-value \\
\hline Early sexual encounter & & & \\
14-15yrs & 21 & 0 & .001 \\
$16-19 y r s$ & 89 & 0 & \\
& & & \\
\hline
\end{tabular}


International Journal of Multidisciplinary Studies and Innovative Research

Publisher: Catholic University College of Ghana

ISSN: 2737-7172(0), ISSN: 2737-7180(P)

DOI: $10.53075 /$ ljmsirq 87965439050

DOI Url: http://doi.org/10.53075/ljmsirq87965439050

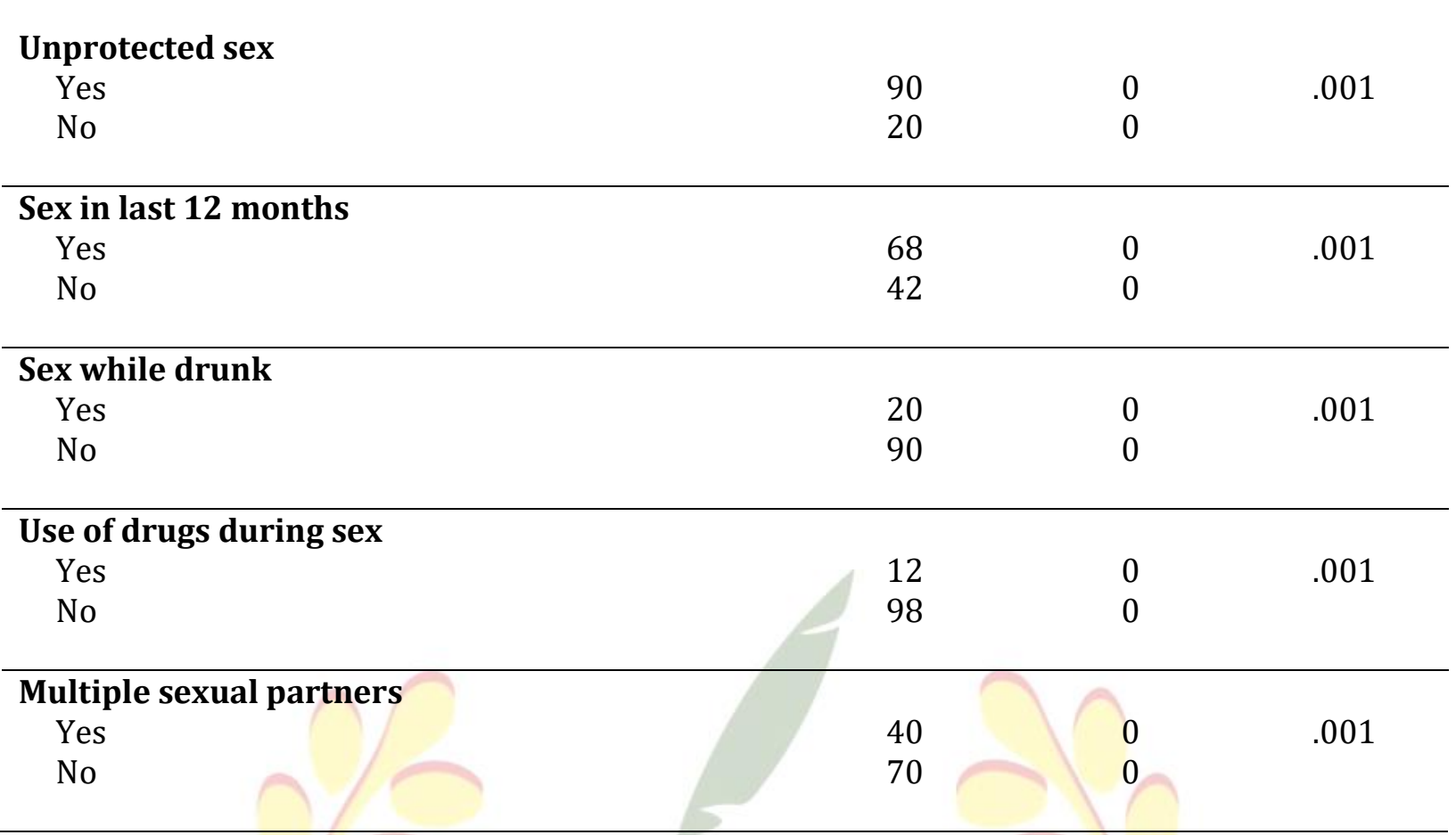

A chi-square test was done at $(\mathrm{p}<0.05)$ significance level and at $95 \%$ confidence interval to ascertain the degree of association between risky sexual behaviours and sexually transmitted infections. It was found that, the age of early sexual encounter $(p<0.001)$, their sexual activity in the last 12 months $(p<0.001)$, sexual activity while drunk $(p<0.001)$, use of drugs during sex $(p<0.001)$, and having multiple sexual partners $(p<0.001)$ all had a strong statistical relationship with the development of STIs (see table 5).

Table 6; Determinants of risky sexual behaviour and development of STIs (Multiple logistic regression analysis)

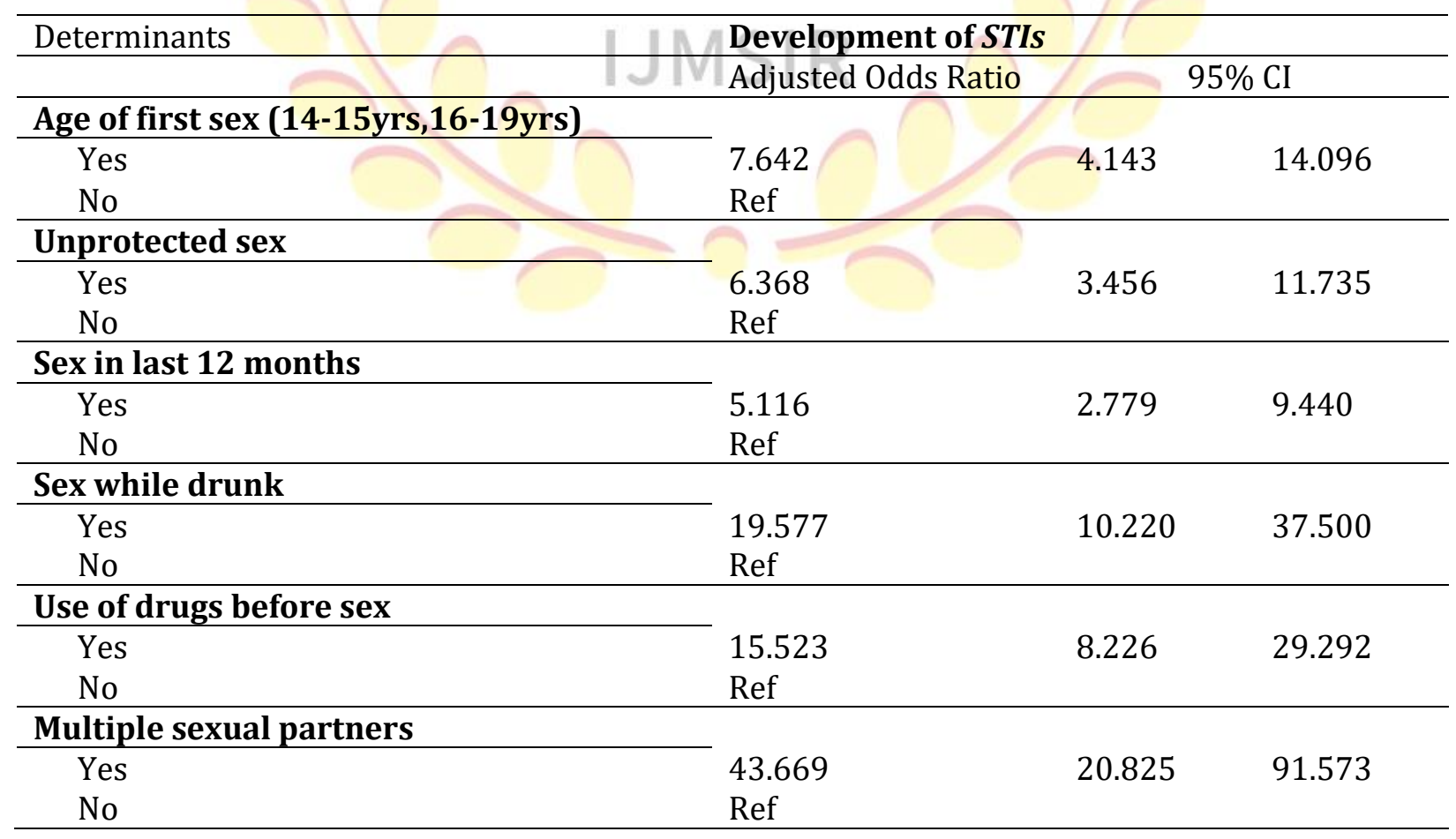




\section{International Journal of Multidisciplinary Studies and Innovative Research \\ Publisher: Catholic University College of Ghana \\ ISSN: 2737-7172 (0), ISSN: 2737-7180 (P) \\ DOI: $10.53075 /$ ljmsirq 87965439050 \\ DOI Url: http://doi.org/10.53075//jmsirq87965439050}

In a multiple logistic regression model, adjusted odds ratios were calculated to control for confounders. Variables that were significant at the chi-square with $\mathrm{p}<0.05$ were selected into the multiple regression model. After controlling for confounders, respondents' Age of first sex (OR 7.462, CI: 4.143 - 14.096) was over seven (7) times more likely to get STIs. Respondents who had unprotected sex (OR 6.368, CI: 3.456 - 11.735) was over six (6) times more likely to get STIs. Respondents who had sex in the last 12 months (OR 5.116, CI: $2.772-9.440$ ) was over five (5) times more likely to get STIs. In addition, respondents who had sex while drunk ( OR 19.577, CI: 10.220 - 37.500) was over nineteen (19) times more likely to get STIs. Respondents who use drugs before sex (OR 15.523, CI: 8.226 - 29.292) was over fifteen (15) times more likely to get STIs. Lastly, respondents who have multiple sexual partners (OR 43.669, CI: 20.825 - 91.573) was over forty-three (43) times more likely to get STIs ( see table 9).

\subsection{DISCUSSION}

The study found that about $44 \%$ of the general respondents' population indulged in varying forms of risky sexual behaviour and $35.6 \%$ indicated having had their first sexual intercourse at ages 15-19 and their counterparts $8.4 \%$ indicated having had their first sexual intercourse at age 14-15. About 36\% indicated having unprotected sex, $14.4 \%$ indicated having 2 sexual partners while $2.8 \%$ indicated having more than 2 sexual partners. About $8 \%$ of the students mentioned having had sex while drunk and 16\% mentioned having had sex for cash.

The above findings are very striking because a situation where $44 \%$ of a student population indulged in different forms of sexual risk behaviours is dangerous since it has a higher propensity to predispose them to sexually transmitted infections. These findings are in tandem with the observations made by Asante et al (2016), who opined that young people within the ages of 15-24 years are at a greater risk of contracting STIS including HIV due to high prevalence of sexual risk behaviours at that age.

Imagine students having had their first sexual encounter as young as age 14 . Imagine $36 \%$ of students having unprotected sex indiscriminately and just imagine students having multiple sexual partners at that young age. Another disheartening aspect of this finding is seeing these young students abusing alcohol, smoking and using other drugs and afterwards indulging in sexual acts. The ease of internet access in this modern age could have accounted for this high prevalence of sexual risk behaviours among the youth as young people want to explore whatever they see on the internet. It is also possible that loss of parental control which could have been triggered by broken homes which is very common in the Ghanaian societies and bad peer influence could be acting as the catalysts to drive these unacceptable acts. For young people to indulge in sexual acts just to gain financial benefits is an indicator of an underlying social problem, specifically poverty and deprivation which ought to be tackled by successive governments.

The study further sought to find out the rationale behind the $36 \%$ of the students who indulge in unprotected sex. $24 \%$ said because condom is not available to them, $13.6 \%$ claimed to have never heard of condom, $18.8 \%$ said it is because they could not negotiate with their sexual partners (especially the females), and $28 \%$ perceived that, there is decreased sexual sensations with condoms and hence lowers sexual pleasure. Such perceptions towards condom use are highly erroneous and needs to be urgently dispelled since non-condom use increase the likelihood of contracting sexually transmitted infections among the youth.

In another study by Dartey \& Nnorom (2012) among adolescents in poor urban towns in the then Brong Ahafo region, they found that adolescents in the two communities were indiscriminately engaging in high sexual activities as has been found in this current study. In spite of this existing menace, condom use among the adolescents was lacking thereby increasing their likelihood of contracting STIS and this current study affirms same.

The preceding findings further consolidate the observations made by Brouillette (2013) to the fact that having multiple sexual partners, non-condom use and drug use have been classified as behavioral factors that are deemed risky for the transmission of STIs worldwide.

The results indicated that only $21.2 \%$ respondents were found to have high STIs risk perception whereas a greater majority of $78.8 \%$ had low STIs risk perception. This higher percentage of low STI risk perception is not surprising especially when only $34.3 \%$ perceived there was high incidence and prevalence of STIs among the people within the society and also about $67.25 \%$ believed they were 


\section{International Journal of Multidisciplinary Studies and Innovative Research \\ Publisher: Catholic University College of Ghana \\ ISSN: 2737-7172 (O), ISSN: 2737-7180 (P) \\ DOI: $10.53075 /$ ljmsirq 87965439050 \\ DOI Url: http://doi.org/10.53075/ljmsirq87965439050}

rationally safe from STIS even after having unprotected sexual intercourse. Similar low perceptions were replicated across all 5 statements which yielded the above finding.

Risk perception connotes people's subjective judgment about the severity of a risk and in the context of STIs, the greater the percentage of a highrisk perception the better. Since with higher risk perception, young people would take strong steps to prevent themselves from contracting STIs. It is disturbing therefore to observe the fact that young people are not afraid of STIs to the extent that a great majority believe they are safe from STIs even after having unprotected sex. This low STI risk perception may have motivated the $36 \%$ of the students to indulge in raw sex as earlier observed.

Indiscriminately indulging in risky sexual behaviour means that young people do not consider the negative health consequences associated with it but rather look out for the related quick pleasure that accompanies risky sexual behaviours. The observation emanating from this current study affirms similar findings made by Ntaganira et al (2012) in their study in Rwanda where they shockingly found that majority $(68.9 \%)$ of respondents indicated that they were at no risk of contracting an HIV infection but only a meager 3.2\% indicated that they were at a high risk of contracting an HIV infection. This is very alarming considering the huge negative repercussions that are associated with such a perception especially when HIV is at the center.

Several studies have established a significant association between young people's risky sexual behaviors that place them at a high risk of contracting sexually transmitted infections and this current study is no exception. Both the chi-square test and the multiple logistic regression analysis established strong statistical relationship between the sexual risk behaviours that young people indulge in and the likelihood of contracting STIs. Such risky sexual behaviours included early sexual encounter, noncondom use, multiple sexual partners and the use of drugs which highly stimulate young people to engage in indiscriminate sexual acts.

And this study further consolidates the observations made by Dubravko et al (2013), Spauwen et al (2015) and Adefuye et al (2009) who all opined that the aforementioned sexual risk behaviours possess an enormous propensity to increase the potentiality of young individuals to contract sexually transmitted infections. Undeniably, the above findings rhyme with scientific facts as there is no contrary empirical evidence which can dispel the fact that having unprotected sexual intercourse increases the probability of acquiring STIs. In the same vein, having multiple sexual partners only puts individuals at a higher risk of acquiring sexually transmitted infections especially when the $A B C s$ of $H I V$ and other STIs prevention lays strict emphasis on faithfulness to one sexual partner. Additionally, early sexual encounter as early as age 14 is a high trigger to contracting STIs due to the fact that at that age, the individual has not matured enough to practice high safe sex etiquettes which make them very vulnerable. The use of drugs, alcohol and other substances cannot be excluded from the list of factors which catalyze young folks to indulge in unsafe sex practices which increases their risk of contracting STIS.

\subsection{CONCLUSIONS}

Premising on the preceding presented results and other findings the study concludes that about $44 \%$ of senior high school students in the target senior high school indulge in various forms of sexual risk behaviours. The study further concludes that a greater majority of senior high school students $(78.8 \%)$ had low STI risk perception which raises a huge public health concern. Sexual risk behaviours such as early sexual initiation, having multiple sexual partners, non-condom use and the use of drugs are strongly associated with the likelihood of contracting sexually transmitted infections.

\subsection{Recommendations}

To address these sexual risk behaviours there is the need for rigorous mass sensitization campaigns across all senior high schools in Ghana to create more awareness among young people on the dangers associated with indulging in risky sexual behaviours. This situation needs to change drastically and mass sensitization campaigns is the key antidote to remedy the situation.

A qualitative-oriented study is recommended to look at the social triggers of sexual risk behaviours in order to come up with other findings which will necessitate new policy initiatives that can help reduce sexual risk behaviours among young people. 


\section{International Journal of Multidisciplinary Studies and Innovative Research \\ Publisher: Catholic University College of Ghana \\ ISSN: 2737-7172 (O), ISSN: 2737-7180 (P) \\ DOI: $10.53075 /$ ljmsirq 87965439050 \\ DOI Url: http://doi.org/10.53075/ljmsirq87965439050}

\subsection{ACNOWLEDGEMENT}

We are grateful to Dr Kofi Bobi Barimah, Mrs. Sandra Adelaide Hanson and Nana Ama Frimpomaa for their help in diverse ways.

\section{REFERENCES}

Adefuye, A. S., Abiona, T. C., Balogun, J. A., \& LukoboDurrell, M. (2009). HIV sexual risk behaviors and perception of risk among college students: implications for planning interventions. BMC Public Health, 9, 281. http://doi.org/10.1186/1471-24589-281

Asante, K. O., Doku, N. P., \& Osafo, J. (2016). The role of condom use self-efficacy on intended and actual condom use among university students in Ghana. Journal of Community Health, 41(1), 97-104. http://doi.org/10.1007/s10900-015-0073-6

Berhan, Y., \& Berhan, A. (2015). A Meta-Analysis of Risky Sexual Behaviour among Male Youth in Developing Countries, 2015.

Brouillette, J. M. (2013). Sexually transmitted infections among college women secondary to high-risk behaviors related to lack of behavioral health interventions. ScholarWorks@UMass Amherst.

Centers for Disease Control and Prevention (2012). Youth Risk Behavior Surveillance-United Sates, 2009. MMWR, 59 (No. SS-5):1-142. Retrieved from http://www.cdc.gov/mmwr/preview/mmwrhtml/s s5905a1.htm

Darteh, E., \& Nnorom, C. C. P. (2012). Sexual behaviour and condom use among Adolescents living in urban poor areas in the. Journal of Alternative Perspectives in the Social Sciences, 4(3), 619-639. article.
Dubravko Lepušić and Sandra Radović-Radovčić. (2013). Alcohol - A Predictor of Risky Sexual Behavior Among Female Adolescents, 3-9. Journal of Adolescence

Kenyon, C., Buyze, J., \& Colebunders, R. (2014). Classification of incidence and prevalence of certain sexually transmitted infections by world regions. International Journal of Infectious Diseases, 18(1), 73-80. http://doi.org/10.1016/j.ijid.2013.09.014

Kugbey, N., Amogre, M., Amu, H., Oppong, K., \& Adam, A. (2018). International note : Analysis of risk and protective factors for risky sexual behaviours among school-aged adolescents. Journal of Adolescence, 68(March),-66-69. https://doi.org/10.1016/j.adolescence.2018.06.013

Ntaganira, J., Hass, L. J., Hosner, S., Brown, L., \& Mock, N. B. (2012). Sexual risk behaviors among youth heads of household in Gikongoro, south province of Rwanda. BMC Public Health, 12(1), 225. http://doi.org/10.1186/1471-2458-12-225

Okonta, M. J., Ubaka, C. M., \& Araukwe, N. N. (2013). Student Demographics and Their Effects on Risky Sexual Behaviors and Poor Condom Use Pattern in Two Departments of a Nigerian University. American Journal of Public Health Research, 1(3), 65-71. http://doi.org/10.12691/ajphr-1-3-2

Rokhmah, D. (2015). The Role of Sexual Behavior in the Transmission of HIV and AIDS in Adolescent in Coastal Area. ScienceDirect, Procedia Environmental, 23 (Ictcred 2014), 99-104. http://doi.org/10.1016/j.proenv.2015.01.015

Spauwen, L. W. L., Niekamp, A.-M., Hoebe, C. J. P. A., \& Dukers-Muijrers, N. H. T. M. (2015). Drug use, sexual risk behaviour and sexually transmitted infections among swingers: a cross-sectional study in The Netherlands. PubMed.gov, 91(1), 31-36. 